\title{
AS EMOÇÕES RACIONAIS E A REALIZAÇÃO PRÁTICA DO DIREITO À LUZ DA PROPOSTA DE MARTHA NUSSBAUM; O PAPEL DAS OBRAS LITERÁRIAS E DAS EMOÇÕES RACIONAIS NO PROCESSO DE TOMADA DE DECISÃO JUDICIAL.
}

\author{
Ana Carolina Faria Silvestre*
}

\begin{abstract}
SUMÁRIO: Introdução; 2. As emoções e as emoções racionais; 2.a. Algumas objeções às emoções; 2.a.i. Emoções como forças animais cegas?; 2.a.ii. Emoções como reconhecimento de carência?; 3. O processo de construção dos pensamentos: um aparte perscrutador!; 3.a. A reconstrução do passado; 4. A neurociência e as emoções; 4.a. Para além dos marcadores-somáticos; 5. O espectador judicioso; 6. Os poetas como juízes; 7. Considerações finais; 8. Referências bibliográficas.
\end{abstract}

\begin{abstract}
RESUMO: Qual será o papel das emoções no processo de tomada de decisão racional e no processo de tomada de decisão judicial, enquanto espécie pertencente ao gênero? A possibilidade de se colocar comprometidamente esta pergunta implica no enfrentamento crítico da posição tradicional, ancorada na tradição filosófica ocidental, que assume uma dualidade estrutural entre as emoções e a razão. As emoções, sustentam, devem ser dominadas ou, preferencialmente, estirpadas do debate racional - revelando-se especialmente nocivas no âmbito da deliberação pública. A decisão racional é também uma decisão não-emotiva e, portanto, um bom julgador, para além de ser uma pessoa intelectualmente dotada de conhecimentos sólidos sobre as leis e sobre as coisas do mundo, deve ser capaz de suprimir suas emoções. No entanto, questiona Nussbaum, será possível decidir um caso com justiça sem a convocação das emoções? Os juízes não são neutros e o seu julgamento convoca-envolve-produz emoções (racionais e irracionais). As emoções racionais não devem ser suprimidas, elas devem ser assumidas em sua inevitabilidade e importância no âmbito do processo racional de decisão e no âmbito da decisão judicial.
\end{abstract}

Palavras-chaves: Emoções racionais; deliberação pública; decisão judicial; realização prática do Direito.

\begin{abstract}
What is the role of emotions in the rational decision-making process and in the judicial decision-making process, as a species belonging to the genre? The ability to put this question in a committed way implies facing criticism from the traditional position, anchored in the Western philosophical tradition, which assumes a structural dualism between emotion and reason. Emotions, they maintain, should be controlled or, preferably, strains of rational debate proving to be particularly damaging in the context of public deliberation. The rational decision is also a non-emotional decision and, therefore, a good judge, in addition to being a person intellectually endowed with solid knowledge about the Law and things about the world should be able to suppress his/her emotions. However, questions Nussbaum, can the judge decide righteously without emotions? The judges are not neutral and their judgments calls-involvesproduces emotions (rational and irrational ones). The rational emotions should not be banished from rational discourse, they must be assumed in their inevitability and importance in the rational decision-making and under the judicial decision-making as well.
\end{abstract}

Key-words: Rational emotions; public deliberation; judicial decision-making; adjudication.

\footnotetext{
* Mestre e doutoranda em Ciências Jurídico-filosóficas na Faculdade de Direito da Universidade de Coimbra - Portugal. Professora-pesquisadora na Faculdade de Direito do Sul de Minas. Pesquisadora do DJDH-NEV/USP. Autora das obras filosófico-literárias intituladas "Vidas à vendas" e "Cidades Impossíveis".
} 


\section{INTRODUÇÃO}

É familiar ao senso comum a assunção da razão e das emoções como dimensões antagônicas, em constante tensão. As emoções são, sob esta divisão asséptica, forças incontroláveis que conduzem os homens a mares bravios ou a calmarias - que se sucederiam ininterrupta e inadvertidamente -, condicionada a sua felicidade ou infelicidade por fatores exteriores ao eu-sujeito. Na outra face da moeda ter-se-ia a razão; luminosa, capaz de levantar o véu que obscurece a verdade, de acedê-la ${ }^{1}$ e de conduzir-nos ao gozo da felicidade imperturbável dos conceitos e das matemáticas.

O predomínio da razão sobre a emoção teria a potencialidade de orientar a ação humana para o bem e, em última análise, nos conduziria à realidade de uma comunidade de iguais ${ }^{2}$. Platão, exemplarmente, compreendia que o acesso à verdade pressuporia o cultivo da faculdade da alma que mais nos assemelhava aos deuses (a razão) e o afastamento do corpo ${ }^{3}$. A alma imortal dos homens entregues à satisfação dos sentidos ganharia corporalidade, impedindo-os de aceder à verdade encerrada no mundo inteligível.

Todos os seres pertencentes ao gênero humano possuiam uma alma imortal, assumia Platão, constituída por diferentes faculdades. A alma apetética, comum às plantas, aos animais e aos homens, relacionar-se-ia aos instintos e aos apetites (baixo ventre). A alma irascível, comum aos homens e aos animais, relacionar-se-ia à vontade como virtude cavalheiresca (peito). Para além, os seres humanos seriam dotados de uma faculdade exclusiva alcunhada de alma logística - a alma logística deveria preponderar sobre as demais, nos capacitando a todos, ainda que em potência, a aceder às verdades encerradas no mundo inteligível.

$\mathrm{O}$ acesso à verdade estava condicionado à racionalização das emoções, dos ímpetos, dos instintos e da vontade ${ }^{4}$, ou seja, ao abandono do corpo e ao

\footnotetext{
${ }^{1}$ Não se trata aqui, certamente, de assumir uma qualquer compreensão ontológico-substancial do mundo e do acesso potencial do homem, porque racional, às verdades. Após as investigações de David Hume e, decisivamente, a teoria da falsificabilidade de Popper, há que se assumir a busca pela verdade como uma tarefa sempre aberta, incompleta e hipotética. $\mathrm{O}$ cientista não pode ser aquele que se resigna a afirmar que todos os cisnes são brancos, mas aquele que está sempre à procura do cisne negro.

${ }^{2}$ Sócrates acreditava no potencial luminoso e desvelador do diálogo. Enquanto pertencentes ao gênero humano - independentemente de nossa situação política, econômica, cultural -, traríamos inscrita em nosso peito a lei natural, inacessível solipcisticamente. $\mathrm{O}$ acesso à verdade, perspectivada enquanto verdade absoluta, nos conduziria à realidade de uma comunidade de iguais.

${ }^{3}$ Segundo Platão, o corpo seria o responsável por todos os embaraços e empecilhos que nos afastariam da verdade. O corpo buscaria a satisfação de seus apetites enquanto a alma objetivaria a sabedoria. Direcionados rumo a objetivos diversos, alma e corpo estariam condenados, enquanto viventes no mundo sensível, à tensão. PLATÃO, Fédon, p. 9

${ }^{4}$ Platão, contrariamente a Sócrates, assume que a verdade não é efetivamente acessível a todos. Para que tenhamos acesso à verdade é necessário, dentre outros fatores, que possamos nos dedicar exclusivamente à sua investigação. Para que a polis seja forte (tanto interna quanto externamente), próspera e feliz é necessário que haja respeito entre as diferentes atividades; é esta a concepção que se delineia no Estado ideal da República de Platão.
} 
cultivo da reta razão. As guerras e os combates, sustentava Platão, estavam imediatamente relacionados à acumulação de riquezas, que servem única e exclusivamente para satisfazer os desejos e caprichos da carne ${ }^{5}$. A restrição da vida à dimensão corpórea condenaria o homem a uma eternidade de sombras e de ilusão. A razão, assim como o cocheiro de uma carruagem, deveria definir a trajetória e guiar com mão firme os impulsos, as paixões e as emoções, sob pena de não mais conseguir corrigir o curso da alma arrastada pelos apelos da carne e da satisfação hedonista dos sentidos. A ataraxia seria o resultado necessário do domínio das emoções pela razão, que tudo penetra e revela um mundo estruturado sob leis ontológico-substancialmente cunhadas.

As investigações platônicas, como sabemos, estavam ancoradas sob uma perspectiva mítico-teológica do mundo e das coisas do mundo. No cerne das afirmações acerca da dualidade de mundos e de justiças, da busca pela verdade encerrada em um plano transcendente de inteligibilidade, da luta perpétua da alma contra o corpo - como condição necessária para o acesso à verdade - estava a crença em um mundo concebido enquanto "dado" (ontológico-substancialmente concebido). Um mundo constituído por (enquanto) leis eternas e imutáveis, criadas em tempos imemoriais e que incidiriam sobre todos os seres, irremediavelmente. $\mathrm{O}$ homem, naquele contexto cultural cunhado pela fatalidade, nada podia fazer em face daquilo "que é", cabendo-lhe somente a atitude de espantar-se ${ }^{6}$ em face do iniludível e do inevitável.

O homem pós-moderno, herdeiro dessa tradição, ainda hoje se questiona acerca da relação entre as emoções e a razão. O passado sugere que a razão nem sempre se revela luminosa ${ }^{7}$ e que as emoções nem sempre nos conduzem ao infortúnio e ao engodo. A supressão das emoções não é "condição necessária" para assegurar uma resposta racional ao caso-problema surgido no mundo da vida e, no limite, ao caso problema-jurídico. No entanto, qual deve ser o tratamento dispensado às emoções no âmbito da realização prática do direito? Esta será uma questão orientadora dessa investigação que assumidamente elege, como horizonte privilegiado de discussão, as investigações de Martha Nussbaum em Poetic Justice.

\section{AS EMOÇÕES E AS EMOÇÕES RACIONAIS}

Martha Nussbaum, em Poetic Justice, dedica-se à defesa da imaginação literária, enquanto catalizadora de emoções racionais, salientando suas contribuições

\footnotetext{
${ }^{5}$ PLATÃO, Fédon, p. 9.

${ }^{6}$ Karl Jaspers identificou três origens principais ou atitudes fundamentais da filosofia, são elas: o espanto, a dúvida e a comoção. JASPERS, K., Einführung die Philosophie apud KAUFMANN, A.; HASSEMER, W., 2002, p. 37.

${ }^{7}$ Em Modernidade e Holocausto, Zigmunt Bauman assinala as lições de alerta e, acima de tudo, de esperança que a experiência dolorosa do Holocausto é capaz de nos ensinar. A desconstrução da modernidade enquanto baluarte luminoso da razão moderno-iluminista acaba por revelar o humano enquanto Janos - deus romano de dupla face -, cuja outra face desconhece a existência. Cf. BAUMAN, Zigmunt, Modernidade e Holocausto.
} 
para a racionalidade pública. A autora assume que a leitura de obras literárias, sobretudo obras literárias realistas ${ }^{8}$, para além de experiências prazerosas, nos permitem experienciar emoções racionais. Dedicar-nos-emos agora a analisar criticamente os argumentos que oferece e as conclusões a que chega, especialmente no âmbito da realização prática do Direito.

A leitura de uma boa obra literária transporta-nos para um outro mundo de possibilidades. A trama que envolve suas personagens também nos envolve seus sofrimentos, suas alegrias, suas decepções têm o poder de transportar-nos, enquanto leitores, para um outro plano de inteligibilidade cunhado pela cumplicidade. Imersos na leitura de um romance, experienciamos emoções vivenciadas por suas personagens que nos provocam e "atingem" enquanto dramas humanos. A leitura de algumas obras literárias tem o potencial de proporcionar aos leitores uma rica experiência imaginativa e empáticoemotiva ${ }^{9}$. Contrariamente à crença assentada de que a razão e a emoção pertencem a reinos diversos, diametralmente opostos, a autora parece se incluir no grupo dos amantes da literatura que defendem a volta dos poetas à república de Platão ${ }^{1011}$, a conciliação entre razão e emoção e, no âmbito da racionalidade pública, a perspectivação de que a decisão mais adequada convoca a razão e as emoções racionais enquanto unidade racional.

A leitura de obras realistas teria a potencialidade de colocar o leitor em uma posição privilegiada em face do problema narrativamente apresentado. $\mathrm{O}$ exercício do "espectador judicioso" é perspectivado enquanto recurso epistemológico e metodológico que revela toda a sua pungência e relevância no âmbito da resolução dos casos difíceis.

8 "Why novel and not other literary genres? The novel is a living form and in fact still the central morally serious yet popularly engaging fictional form of our culture (...) novels (at least realist novels of the sort I shall consider) present persistent forms of human need and desire realized in specific social situations. These situations frequently, indeed usually, differ a good deal from the reader's own. Novel, recognizing this, in general construct and speak to an implicit reader who shares with the characters certain hopes, fears, and general human concerns, and who for that reason is able to form bonds of identification and sympathy with them, but who is also situated elsewhere and needs to be informed about the concrete situation of the characters". NUSSBAUM, 1995, pp. 6-7.

9 "What they feel, will, indeed, always be, in some respects, different from what he feels, and compassion can never be exactly the same with original sorrow; because the secret consciousness that the change of situations, from which the sympathetic sentiment arises, is but imaginary, not only lowers it in degree, but, in some measure, varies it in kind, and gives it a quite different modification. These two sentiments, however, may, it is evident, have such a correspondence with one another, as is sufficient for the harmony of society. Though they will never be unisons, they may be concords, and this is all that is wanted or required". SMITH, A., 1759, p. 72.

${ }^{10}$ NUSSBAUM, M., 1995, p. 54.

${ }^{11}$ A querela entre poetas e filósofos remonta aos pré-socráticos. Platão é seu herdeiro e para compreendêla satisfatoriamente se faz necessária a leitura do diálogo A República. Villela-Petit salienta que a leitura isolada do capítulo X da República nem sempre é suficiente para compreender a dimensão da crítica platônica. No âmago da crítica estaria a corrupção do êthos do indivíduo e da polis. Os poetas, enquanto responsáveis pela paidéia e, portanto, pela formação do êthos deveriam se ocupar da busca pelo saber dialético. VILLELA-PETIT, M. P., 2003, p. 2-21. 


\subsection{Algumas objeções às emoções}

A primeira das objeções oponíveis às emoções equipara-as à forças cegas que nada (ou muito pouco) têm a ver com a razão, o equilíbrio e a ataraxia. As emoções seriam estruturalmente desprovidas de reflexão ou juízo e, portanto, essenciamente muito pouco receptivas aos argumentos da razão. É frequente a associação das emoções aos animais - bestas ingênuas desprovidas de raciocínio e com a sensibilidade à flor da pele. Os homens, enquanto constituídos de razão e emoções, deveriam assumir-se como seres estruturalmente compostos de elementos racionais (razão) e irracionais (emoções). O bom juízo estaria associado, portanto, a eliminação (desejável) das emoções e à hipertrofia do elemento racional. Assim como o vento e as ondas do mar, as emoções conduziriam o sujeito a uma vida desrregrada, caoticamente instável ${ }^{12}$ e deveriam ser, portanto, suprimidas e racionalmente combatidas. É importante salientar que discursos deste tipo, não raro, têm servido como "embasamento teórico" a afirmações sexistas que associam acriticamente as emoções às mulheres e a razão aos homens.

A segunda objeção às emoções nos remete a tradição filosófica ocidental - Platão, Epicuro, os estoicos gregos e romanos e Espinosa - que associa as emoções aos falsos juízos.

As emoções não são perspectivadas como forças cegas, desprovidas de juízo e/ou surdas aos argumentos da razão, mas teriam o condão de conduzir-nos a juízos falsos. As emoções relevariam a importância de pessoas e eventos exteriores ao sujeito, sobre os quais não possui efetivo controle e que podem lhe ser retirados sem aviso - levados definitivamente pelo fluxo constante e ininterrupto da roda da fortuna que gira incessantemente. Nossos pais, irmãos, filhos e amigos queridos a quem, frequentemente, atribuímos grande valor, são "elementos" exteriores ao eusujeito com os quais estabelecemos laços de afeto. Estes laços são, no entanto, frágeis e podem ser destruídos pelo azar. A consciência de nossa impotência e limitação pode gerar sentimentos negativos como o medo, o ciúme e a cólera. A cólera, exemplarmente, sucede-se ao pensamento de que alguém causou grave dano a algo (ou alguém) a que(m) atribuímos grande valor ou estima etc.

As emoções relevariam a incompletude da experiência humana e condenariam o sujeito à inconstância e à perturbação. Segundo os alcunhados "filósofos anti-emotivos", ", no entanto, esta visão emotiva do mundo, cunhada pela fatalidade, é falsa. A sorte ou o azar nada podem fazer contra as coisas efetivamente valiosas; o pensamento e a virtude. Sócrates, por exemplo, insistia

12 "Like gusts of wind or the currents of the sea, they move, and move the person, but obtusely, without vision of an object or beliefs about it”. NUSSBAUM, M., 2001, p. 24.

${ }^{13}$ Martha Nussbaum alcunha Platão, Epicuro, os estoicos gregos e romanos e Espinosa de filósofos antiemotivos. NUSSBAUM, M., 1995, p. 56-57. Tais filósofos teriam em comum a compreensão de que a imagem do mundo que as emoções nos revelam (a par de estarem relacionadas aos juízos) é falsa. Concordam todos que o homem sábio é aquele que hipertrofia a dimensão interior (que nos é constitutiva) e que atribui pouco ou nenhum valor aos bens materiais e, de forma geral, a tudo o que lhe é exterior. 
com todos aqueles com quem estabelecia diálogo que buscassem compreender a lei natural que os constituía. A verdade desvelada através do diálogo se nos imporia como guias para a ação virtuosa - a educação das almas nos conduziria, em última análise, à consecussão de uma comunidade de iguais e à eudaimonia. A promessa de conhecimento e felicidade estava ancorada, portanto, em uma necessária volta para o interior, para uma dimensão de interioridade que nos constituía e que encerraria em si os conceitos de bem e de mal, de justo e de injusto, de utilidade e de inutilidade etc. A liberdade racional se opunha frontalmente à consagração de emoções, negativas ou positivas, como a paixão, a aflição, a piedade etc; emoções constitutivas e exortadas pelo gênero trágico.

Uma terceira objeção analisada pela a autora questiona o pretenso relevo das emoções no âmbito da deliberação pública. Segundo os seus signatários, as emoções seriam incapazes de considerar um objeto em abstrato, como um objeto entre muitos outros. As pessoas a quem devotamos o nosso amor ou por quem nutrimos ódio ou rancor têm relevância em nossa vida. As emoções, por se concentrarem em laços ou apegos reais de uma pessoa, permaneceriam sempre "perto de casa" e deveriam se perspectivadas como referências de primeira pessoa. Não se inflamariam em face de vidas distantes, nem de sofrimentos invisíveis; motivos suficientes, segundo o ponto de vista da teoria moral utilitarista e inclusive Kantiana, para serem eliminada de uma norma pública de racionalidade.

A quarta e última objeção está inegavelmente relacionada a anterior. Assume que as emoções relevam, de forma demasiada, a dimensão individual, deixando de parte as unidades sociais maiores, tais como as classes. A exacerbação da dimensão do indivíduo e das emoções sutis denunciaria uma verdadeira inabilidade para perceber o político. A perspectivação do domínio ético apartado do domínio político - enquanto duas dimensões estanques - não teria qualquer valor.

\subsubsection{Emoções como forças animais cegas?}

A autora, apesar de pontuar a priori que tal concepção das emoções possui respaldo acadêmico incipiente, gozando de alguma credibilidade apenas em reflexões e conversas informais, enfrenta-a. Convocando filósofos como Platão, Aristóteles, os estoicos gregos e romanos, Espinoza e Adam Smith nos chama a atenção, primeiramente, para a importância de se distinguir emoções de impulsos corporais.

As emoções, diferentemente de impulsos corporais, tais como a fome e a sede, por exemplo, estão diretamente relacionadas a um objeto. Os impulsos corporais são o resultado físico de um processo biologicamente justificado e orientado, enquanto as emoções estão umbilicalmente ligadas à descrição intencional de um objeto específico. A raiva, portanto, não pode ser perspectivada como um mero impulso, uma vez que está sempre direcionada a um objeto específico - a uma pessoa, por exemplo, que, sob a minha análise, teria agido com injustiça relativamente a mim, a algo ou a alguém a quem 
atribuo valor. O que nos levaria a concluir, com Martha Nussbaum, que o modo de perceber um objeto é essencial para o caráter da emoção ${ }^{14}$.

As emoções, para além, estão intimamente ligadas às crenças. A par do flagrante dissenso acerca do tratamento do tema no âmbito da tradição filosófica ocidental $^{15}$ - aqueles iminentes filósofos - a par das especificidades que individualizam o seu contributo - estariam inclinados a concordar com a afirmação genérica de que as emoções respondem de tal modo a diversas crenças que não poderiam existir sem elas. A emoção da piedade está (pelo menos) estreitamente associada à crença de que alguém está sofrendo de forma significativa; a emoção da raiva está iniludivelmente associada à crença de que eu - ou alguém por quem nutro sentimentos positivos - sofri(eu) danos de qualquer ordem devido a ação ou inação intencional de um terceiro. A autora afirma que algumas dessas crenças podem estar profundamente arraigadas em nossa psicologia, não sendo possível afastá-las simplesmente através da convocação de argumentos racionais, logicamente estruturados ${ }^{16}$.

As crenças são elementos fundamentais para a identificaçãoindividualização de uma emoção. Para que sejamos capazes de definir e individualizar uma determinada emoção não é suficiente a convocação analítica da sensação que nos invade, impõe-se, como absolutamente necessária, a investigação das crenças que se vinculam à experiência emocional. As crenças podem ser falsas ou verdadeiras, racionais ou irracionais, apropriadas ou inapropriadas ao seu objeto. Tomemos um exemplo breve: "A" acaba de comprar o carro dos seus sonhos, mas antes mesmo de gozar de sua nova aquisição é convocado pela empresa a viajar a negócios. "A" é forçado a deixar seu carro novo aos cuidados do zelador do prédio onde vive, que se compromete a cuidar do bem. Ao regressar de viagem, "A" se desloca rapidamente à garagem do prédio mas não encontra indício sequer de seu carro. Imediatamente procura pelo zelador sem obter êxito. Já nervoso, liga a todos os que talvez pudessem lhe dizer algo acerca do paradeiro do carro ou do zelador, sem qualquer resultado. Com o passar dos minutos, que subtamente lhe parecem horas, uma grande cólera se apodera de "A". Este sentimento está ancorado na crença de que o zelador, dolosa ou culposamente, foi o responsável pelo desaparecimento de seu carro. " $A$ " não sabe que seu carro foi deslocado para o piso superior devido às fortes chuvas da noite anterior. A crença associada à emoção que vivencia é, ao mesmo tempo, falsa, racional e apropriada. As emoções sempre envolvem apreciação e avaliação ${ }^{17}$.

14 "Emotions, in short, whatever else they are, are at least in part ways of perceiving". NUSSBAUM, M., 1995 , p. 61.

${ }^{15}$ A relação entre as emoções e as crenças é tema nomeadamente controverso. Para alguns filósofos as crenças relevantes eram condições necessárias para a emoção. Havia quem sustentasse, no entanto, serem elas condições necessárias e suficientes. Outros afirmavam serem as crenças parte constitutiva das emoções, posição rechaçada por entendimentos que compreediam as emoções como uma classe de crença ou de juízo.

${ }^{16}$ NUSSBAUM, M., 1995, p. 61.

17 "I shall argue that emotions always involve thought of the object's salience or importance, in that sense, they always involve appraisal or evaluation". NUSSBAUM, M., 2001, p. 23. 
A tarefa de valoração de uma emoção necessariamente nos remete à dimensão das crenças (que as constitui, informa ou sustenta). Uma emoção, portanto, pode ser irracional em sentido normativo, mas isto não significa necessariamente que esteja divorciada da cognição e do julgamento ${ }^{18}$.

Ambos os enfoques cognitivos analisados supra podem ser convocados para rechaçar a primeira objeção às emoções. Não podemos concordar, portanto, com a simples (e simplista) afirmação de que as emoções são forças irracionais, totalmente divorciadas da razão e do juízo.

\subsubsection{Emoções como reconhecimento de carência?}

Segundo os antigos estóicos, o homem sábio é aquele que compreende haver nascido para desempenhar um determinado papel - aquele que empreende esforços no sentido de compreender qual é este papel e se dedica a desempenhálo bem - e aceita, acima de tudo, que não pode alterar a ordem das coisas ou as pessoas que o cercam. A felicidade é acessível a todo aquele que caminha de encontro à ataraxia - ao estado de imperturbabilidade da alma em face dos fenômenos e objetos externos.

As emoções nos remetem ao que está fora de nosso controle, tolhem nossa liberdade e estimulavam as nossas carências. Para que tenhamos uma vida mais satisfatória devemos assumir uma atitude anti-emotiva radical, sustentada no distanciamento, no culto da virtude e a passividade em face daquilo que não podemos mudar. A educação, segundo a racionalidade estóica, se opõe frontalmente a educação literária e à visão de mundo que aquela estimula e constrói. Ao invés do dramatismo e da tensão - características inerentes à tragédia clássica -; advoga-se em favor da estabilidade, do distanciamento e da liberdade racional.

Não obstante, será possível pensar a vida comunitária assumindo uma atitude anti-emotiva radical? Nussbaum sustenta que não. A piedade e a compaixão, por exemplo, vinculam-se frequentemente à beneficência, enquanto a sua castração parece estar associada ao egoísmo. Na maioria dos casos, ela também está associada ao reconhecimento de que o mal que recai hoje sobre a vida do outro, pode recair sobre a minha vida ou sobre a vida de alguém que me é caro amanhã. Uma pessoa privada de valorações tais como aquelas facultadas pela piedade, conclui a autora, parece estar privada de uma informação ética fundamental, sem a qual seria impossível valorar racionalmente ${ }^{19}$.

Segundo a autora, a leitura de algumas obras realistas teria o condão de propiciar aos seus leitores a experiência e o exercício da piedade; pedra angular da plena racionalidade social ${ }^{20}$. Esta experiência complexa, afirma Nussbaum, revela-se

\footnotetext{
18 "In no case will emotions be irrational in the sense of being totally cut off from cognition and judgment". NUSSBAUM, M., 1995, p. 63.

${ }^{19}$ NUSSBAUM, M., 1995, p. 65.

${ }^{20}$ Segundo Nussbaum, o sentimento suscitado pelo sofrimento das personagens da trama é de verdadeira piedade e não de empatia. $\mathrm{O}$ espectador de novelas - ao menos as novelas eleitas como adequadas julga que os infortúnios que atingem as personagens são graves e que surgiram sem a sua culpa, tais juízos nem sempre seriam acessíveis dentro da perspectiva empática. NUSSBAUM, M., 1995, p. 66.
} 
essencial para se obter a plena medida da adversidade e do sofrimento alheios valorações necessárias para uma plena racionalidade social ${ }^{21}$.

Tentativas "puramente racionais" de tomada de decisão, desprovidas de emoção, portanto, revelar-se-iam estruturalmente falhas e, não raro, conduziriam a respostas socialmente indesejáveis-inadequadas. A exclusão das emoções do processo de tomada de decisão implicaria na retirada de informações necessárias para uma reação plenamente racional em face do sofrimento alheio ${ }^{22}$.

Em Tempos difíceis, obra realista recorrentemente convocada por Nussbaum, temos dois exemplos bastante pontuados acerca de como o estímulo ou a castração das emoções - especialmente na infância ${ }^{23}$ - poderiam repercutir na tomada racional de decisão e, em última análise, na possibilidade ou impossibilidade de vivenciar o sentimento da felicidade.

Sissy Jupe é filha de um artista circense em decadência. Foi criada e educada em um circo humilde, uma verdadeira comunidade onde parecem vigorar a cumplicidade, a solidariedade e o culto ao lúdico em detrimento das matemáticas e da lógica. Talvez tenha sido a vida humilde de Sissy que a tenha estimulado a perspectivar o sofrimento alheio, individual ou coletivo, de forma piedosa. A hipertrofia da dimensão das emoções, propiciada por uma educação humanista, teria capacitado Sissy a perspectivar o sofrimento alheio com piedade - motivo de seu absoluto fracasso nas aulas de economia (orientada por uma iniludível concepção utilitarista).

Luisa Gradgrind, no polo oposto, foi desde a tenra infância estimulada a conceber o mundo cientificamente. Ao invés de brinquedos, os prodigiosos filhos do Sr. Gradgrind tinham laboratórios de química para conhecer o mundo que os rodeava. $\mathrm{O}$ circo, a música, a leitura de obras fantásticas estavam absolutamente proibidas para Luisa porque, segundo a convicção sincera de seu pai, em nada contribuiriam para a sua educação intelectual e moral. As emoções estavam associadas às pessoas financeiramente menos providas, pouco educadas e menos racionais (ou mais irracionais). Luisa foi estimulada a sufocar suas emoções - a banalizá-las enquanto meros impulsos -, a tomar decisões maximizadoras, assim como deve agir uma boa gestora ou uma boa economista. Este teria sido o motivo fundamental de seu fracasso em compreender os dramas das pessoas de sua comunidade e, no tocante ao âmbito privado, de sua infelicidade.

\footnotetext{
21 "This complex cast of mind is essential in order to take the full measure of the adversity and suffering of others, and that this appraisal is necessary for full social rationality". NUSSBAUM, M., 1995, p. 66

${ }^{22}$ Contrariamente à concepção estóica, a retirada das emoções de quaisquer julgamentos que se pretendam racionais nos impediria de apreender o mundo em plenitude e de julgar racionalmente. A invés de empreender esforços no sentido de dominar ou castrar as emoções, os sábios contemporâneos deveriam assumir o papel essencial que as emoções possuem no processo de tomada de decisão racional, enquanto elementos essenciais do bom julgamento.

${ }^{23}$ Segundo Nussbaum - e assumidamente em concordância com Aristóteles - os laços íntimos de amor e gratidão entre pais e filhos, formados na primeira infância e nutridos na infância, parecem ser indispensáveis pontos de partida para que um adulto se torne capaz de fazer o bem no mundo social. NUSSBAUM, M., 1995, p. 69-70.
} 
Nussbaum entende que a leitura de obras literárias como "Tempos Difíceis" pode estimular seus leitores e leitoras a experienciar emoções como a piedade, pedra angular da plena racionalidade social. No entanto, resta-nos problematizar, quais obras deveriam ser perspectivadas como corretas e quais deveriam ser compreendidas como incorretas segundo o objetivo assumido de propiciar aos leitores uma experiência emocional valiosa em termos comunitários $^{24}$ ? Ainda que uma junta de expertos conseguisse chegar à fixação provisória de tão desejada lista, poder-se-ia afirmar que alguém, após a leitura completa de todas as obras elencadas, seria agora mais capaz de tomar decisões racionais do que outra que não teve acesso àquelas obras?

Uma boa obra literária tem a potencialidade, certamente, de nos transportar para o mundo de suas personagens e seus dramas. A obra "Tempos difíceis" pode ser perspectivada, portanto, como um possível agente catalizador de emoções racionais, tais como a piedade. Não obstante, o contato emotivo do leitor com a obra parece estar irremediavelmente relacionado às características pessoais do eu-leitor, condicionado, portanto, em certa medida, por elementos como a sua história de vida, a sua circunstância atual, as suas aspirações, seus desejos etc ${ }^{25}$. Não pretendemos, no entanto, oferecer com este breve argumento uma real objeção à teoria das emoções racionais de Martha Nussbaum. Nosso intuito é apenas o de problematizar o alcance metodológico-pedagógico de sua teoria no universo da realização prática do Direito. Tendo como norte este nosso objetivo urge investigar, ainda que brevemente, como se constróem os pensamentos e as emoções. O que nos tem a dizer duas investigações exemplares no âmbito da psicologia e da neurociência, respectivamente?

\section{O PROCESSO DE CONSTRUÇÃO DOS PENSAMENTOS: UM APARTE PERSCRUTADOR!}

Nosso objetivo será agora o de investigar alguns pensamentos contemporâneos que procuram compreender os intrincados meandros da mente a fim de lançar luz sobre o processo de construção do pensamento no âmbito da tomada de decisão racional.

\footnotetext{
${ }^{24}$ Martha Nussbaum concebe a figura de um leitor ideal capaz de se emocionar com os dramas alheios - de experimentar emoções a partir da leitura de obras literárias realistas. Acredita, para além, que este contato é capaz de apurar suas valorações acerca da medida da adversidade e do sofrimento alheios. Na esteira da distinção concebida por ECO quanto ao leitor-modelo semiótico e ao leitor-modelo semântico, parece ser correto afirmar que o leitor ideal perspectivado pela autora deve ser capaz de interpretar semioticamente os textos literários. O leitor deve ser capaz de, em face da manifestação linear do texto, enchê-lo de sentido (interpretação semântica) e, para além, de compreender criticamente como o texto estruturalmente o faz. Compreendemos que as valorações pressupõem estes dois tipos de interpretação. ECO, H., 1990, p. 33-43.

25 As investigações de Darwin nos obrigaram a perspectivar-nos, ainda que contra a nossa vaidade, enquanto homo sapiens; seres pertencentes a uma espécie, assumida ela mesma segundo uma perspectiva evolucionista e, portanto, em constante transformação, em iniludível tensão adaptativa com o meio (natural-artificial) e no âmbito do qual nossa condição moral se constrói, desconstrói e se reconstrói. DARWIN, C. A origem das espécies.
} 
Augusto Cury afirma que os pensamentos conscientes têm a sua origem nos pensamentos inconscientes, os chamados pensamentos essenciais. Segundo o investigador, a memória (a memória de uso contínuo e a memória existencial) não pode ser perspectivada como um baú repleto de lembranças que o pensamento dialético (consciente) simplesmente acessa e utiliza como sustentáculo para as suas tomadas racionais de decisão. Todas as experiências psíquicas (ideias, raciocínios analíticos, angústia existencial etc) e as informações psíquicas (nomes, números etc) são armazenadas na memória como sofisticados sistemas de códigos fisico-químicos ${ }^{26}$. Tudo o que vivemos que vemos, que ouvimos, que sentimos, que experienciamos através dos sentidos, que aprendemos etc - todas as experiências que se sucedem em nossas vidas, desde a vida intra-uterina, são reduzidas a representações psicosemânticas (RPS) na memória. As RPS's representam o significado ou o conteúdo das experiências psíquicas e das informações psíquicas ${ }^{27}$.

Ao convocarmos um evento pretérito não estamos, portanto, recordando no sentido rigoroso do termo. Não se trata de (re) viver algo, de um resgate puro e imediato de informações armazenadas, mas de uma organização (sempre atual e nova) das representações psico-semânticas resultantes de um evento passado. A leitura da memória não é um processo consciente, trata-se de uma inevitabilidade realizada diariamente, milhares de vezes ${ }^{28}$, e com distorções ${ }^{29}$. $O$ processo de arquivamento da memória, nos diz o autor, não é segmentado como nos computadores. Nestes, as informações são convertidas em sequências de números e códigos que são armazenadas em arquivos segmentados. O acesso a uma informação pretérita se dá de forma imediata através da conversão da sequência binária em informação, segundo estreitos parâmetros lógicomatemáticos. $\mathrm{O}$ processo de armazenamento das informações na mente humana é muito mais complexo e, ironicamente, menos racional. A leitura da memória humana, defende Cury, não é unidimensional, mas multifocal. Uma singela flor, por exemplo, pode nos remeter a lembranças de nossa infância que nada têm a ver com a sua anatomia. Do mesmo modo, uma simples atitude de uma pessoa

${ }^{26}$ Cury afirma que as informações psíquicas são mais objetivas do que as experiências psíquicas. Poderíamos concluir, portanto, que as RPS's que representam aquelas, na memória, seriam mais bem organizadas do que as RPS's que representam estas. CURY, A., 2006, P. 96.

${ }^{27}$ CURY, A., 2006, p. 96.

28 "Quando estudarmos os fenômenos que lêem a memória e constroem os pensamentos, constataremos que ler e utilizar as riquíssimas matrizes de informações não é uma opção do "eu", mas uma inevitabilidade. Ler e utilizar a memória independe da determinação do "eu". Podemos, no máximo, selecionar a leitura e a utilização da memória. Se fosse possível abortar a leitura da memória em um determinado momento, perderíamos a consciência de quem somos e de onde estamos". Cury, A., 2006, 73.

${ }^{29}$ Para além, no tocante às experiências psíquicas, o autor assume que dentre tais experiências existem distinções quanto ao nível de organização na memória. As RPS's que representam os pensamentos existenciais e os raciocínios analíticos, por exemplo, seriam mais bem organizadas na memória do que as experiências psíquicas que deram origem às RPS's iniciais. CURY, A., 2006, P. 96. 
pode conduzir-nos a experienciar sentimentos de angústia, alegria, medo etc ${ }^{30}$, por provocarem a leitura da memória que resgata conteúdos de nossa história ${ }^{31}$.

\section{1. A reconstrução do passado}

Em A misteriosa chama da Rainha Loana, Humberto Eco explora o universo de um homem que se vê privado de sua memória. Estranhamente, este homem se recorda de todos os fatos e eventos não emotivos de sua vida pretérita, mas não consegue aceder àqueles outros associados imediatamente às emoções. Lembra-se, portanto, de grande parte das informações apreendidas de suas inúmeras leituras, mas não é capaz de se lembrar que é casado e tem filhos. Este homem, incapaz de aceder a porções de sua memória, é convocado a mergulhar em seu passado em busca de si mesmo. Neste processo de busca, isola-se na casa onde passou alguns dos melhores anos de sua infância, acreditando que talvez os sentidos lhe remetam a alguma lembrança de seu passado, de suas aspirações, de suas frustrações, alegrias, dores etc e que, se lembrando de quem era, possa voltar a sê-lo. Acaba por concluir que tal empresa nunca terá êxito, uma vez que já não é mais quem costumava ser. Ainda que se lembrasse do passado e de quem costumava ser, os eventos do presente e do passado mais recente já o haviam mudado. Se lembraria, sempre com distorções, de um outro "eu" que não mais existia. Assim ocorre todos os dias, de forma paulatina e silenciosa. As lembranças não estão armazenadas em algum lugar da mente e, portanto, acessíveis à convocação do intelecto racional. $\mathrm{O}$ processo de volta para o passado não deve ser compreendido como um simples resgate de memórias, mas como um exercício de construçãointerpretação. Cury afirma - convocando diferentes marcos teóricos do que Eco, mas com resultados semelhantes - que a lembrança do passado é uma reconstrução interpretativa da experiência original através da leitura multifocal da história intrapsíquica e dos sistemas de variáveis intrapsíquicas do presente, que atuam psicodinamicamente nestas experiências ${ }^{32}$.

Ao convocarmos a morte de um ente querido, por exemplo, não somos capazes de (re)viver, no sentido rigoroso do termo, a mesma emoção experienciada no passado. A história existencial, afirma o autor, está morta ${ }^{33}$. Para que possa ser utilizada na confecção das cadeias de pensamentos e nas transformações da energia emocional, nossa história existencial tem que ser reconstruída interpretativamente; um processo sempre passível de inúmeras distorções.

${ }^{30} \mathrm{O}$ autor opta por dizer que os gestos, mesmo os mais simples, podem causar reações de alegria, angústia ou ansiedade. Optamos, no entanto, por não falar em reações, mas em emoções na esteira da distinção assumida por Martha Nussbaum entre as emoções e as reações. Compreendemos que mesmo as chamadas "reações fóbicas" devem ser perspectivadas, no âmbito desta distinção, como emoções.

${ }^{31}$ Ambos os exemplos foram retirados da obra de Cury. CURY, A., 2006, p. 100.

${ }^{32}$ CURY, A., 2006, p. 101.

${ }^{33}$ CURY, A., 2006, p. 101. 
O fenômeno RAM registra automaticamente as experiências do passado na memória do córtex cerebral. Os pensamentos e emoções experienciados no palco de nossas mentes são registrados em forma de sistemas físico-químicos (RPS). As RPS's são representações físicas das experiências psíquicas, sempre "pobres" emocionalmente em relação às experiências originais. Não obstante o exposto, a redução da experiência emocional às RPS's não deve ser perspectivada como déficit ou prejuízo. O objetivo essencial da memória, nos diz Cury, é ser utilizada para produzir continuamente novas experiências, ideias, pensamentos, emoções etc. Este processo tem a potencialidade de promover (ou provocar) a evolução psicossocial, o desenvolvimento da personalidade e da inteligência como um todo ${ }^{34}$.

Parece-nos correto concluir que algumas das investigações mais atuais sobre a mente - cenário em que se increvem também as investigações de Cury seriam simpáticas a utilização pedagógica de obras literárias como um, dentre outros instrumentos possíveis, potencialmente capazes de estimular o refinamento da percepção empática dos sofrimentos alheios ${ }^{35}$, uma vez que assumem o homem essencialmente enquanto homo interpres ${ }^{36}$. No entanto, esclarece o autor, a relação qualitativa entre o estímulo socioeducacional, o processo de construção do pensamento e a história psíquica é parcial, pois dependerá da ação psicodinâmica de inúmeras variáveis intrapsíquicas ${ }^{37}$.

Enquanto seres constituídos por uma história intrapsíquica sempre aberta, que se constrói e se (re)significa contínua e ininterruptamente (em condições de normalidade), nossa capacidade empático-emotiva pode ser refinada através das experiências psíquicas que experienciamos no palco de nossa mente. A leitura de algumas obras literárias pode ser perspectivada, em termos psicológicos, como um exercício arrojado de leitura interpretativa da memória existencial que confere realidade psíquica aos códigos físicos "frios" contidos na memória. Reversamente, a experiência empático-psíquica atual, uma vez codificada, passa a integrar a memória existencial; resignificando-a. No entanto, nos parece problemático e extremamente temeroso afirmar que tal exercício seja efetivamente capaz de introduzir uma diferença prática no âmbito do Direito, como conclui Nussbaum" ${ }^{38}$.

A cada instante o "eu sou" dá lugar ao "eu fui” histórico, ou seja, o "eu sou" sofre o caos psicodinâmico e se transforma em história psíquica. A

\footnotetext{
${ }^{34}$ CURY, A., 2006, p. 102.

35 "A respeito dos estímulos socioeducacionais nos processos de construção dos pensamentos, a relação qualitativa entre eles com as construções psicodinâmicas (experiências psíquicas) e, conseqüientemente, com a formação da história intrapsiquica, não é completa, mas parcial, pois dependerá da ação psicodinâmica de múltiplas variáveis intrapsíquicas”. CURY A., 2006, p. 108.

${ }^{36}$ Cury afirma que o homo intelligens é resultado do homo interpres. "O homo interpres é o homem inconsciente, representado pelos territórios da memória e pelo conjunto dos fenômenos inconscientes que produzem o funcionamento da mente". Cury, A., 2006, p. 93.

${ }^{37}$ CURY, A., 2006, p. 107.

38 "Getting clear about the unexamined contrast between emotion and reason thus makes a practical difference in the law". NUSSBAUM, M., 1995, p. 55.
} 
existência do "eu" pressupõe a destruição do "eu"; entre presente e passado há uma relação dialética ininterrrupta (e, no limite, imprevisível) de construçãodesconstrução ${ }^{39}$.

\begin{abstract}
O caos do "eu sou" expande a história intrapsíquica, ou seja, a descaracterização das experiências do presente expande o registro da memória. Para que possamos enriquecer nossa capacidade de pensar e de sentir do presente, precisamos enriquecer nossa memória. Todavia, para enriquecer a memória, os pensamentos e as emoções do presente têm que "morrer" e se registrar nela. "Morrendo", descaracterizando-se, eles abrem espaços para novas leituras da memória e para a produção de novos pensamentos e emoções $^{40}$.
\end{abstract}

Nossos pensamento e emoções estão em constante evolução, o que não significa necessariamente que tal evolução se dê em termos qualitativos ${ }^{41}$. A mente humana não é estritamente lógica, estável; cuja nota tônica seria a mesmice intelectual. Algumas das características mais marcantes da mente humana são: a diferenciação na produção intelectual, a distinção e a evolução ${ }^{42}$.

\title{
4. A NEUROCIÊNCIA E AS EMOÇÕES
}

Algumas investigações contemporâneas no âmbito das neurociências corroboram a afirmação de que a ação das emoções, para além dos impulsos biológicos e dos estados do corpo, pode ser uma base indispensável para a racionalidade ${ }^{43}$.

Decisões de caráter pessoal/social e decisões de caráter não pessoal/social, apesar das diferenças manifestas quanto à matéria e ao nível de complexidade, teriam um mesmo fio neurobiológico comum. Segundo Damásio, Descartes, Platão e Kant se equivocaram ao afirmar que os melhores resultados pressupõem o afastamento das emoções ${ }^{44}$. Análises frias de custo e benefício, orientadas pela utilidade subjetiva, parecem incapazes de resolver mesmo os problemas comumente alcunhados como simples. Um homem que se vê confrontado com a necessidade de escolher entre um negócio lucrativo ou a manutenção de uma amizade sincera, terá que analisar as consequiências de sua decisão em diferentes pontos do futuro e calcular as perdas e danos daí

39 O "eu sou", não obstante, tem dimensões distintas do "eu fui”. Ele representa o "eu fui”" histórico somado às variáveis intrapsíquicas do presente. Cury, A., 2006, p. 104

${ }^{40}$ Grifo nosso. CURY, A., 2006, p. 103.

${ }^{41}$ Segundo Cury, na gênese da ansiedade está na leitura contínua de determinadas zonas da memória que produzem reações ansiosas que são descaracterizadas e registradas novamente, (retro) alimentando áreas doentias de nossa história. CURY, A., 2006, p. 104.

${ }^{42}$ CURY, A., 2006, p. 104.

${ }^{43}$ DAMASIO, A. R., 2005, P. 210.

${ }^{44}$ Segundo Damásio, a sua experiência com doentes com lesões pré-frontais sugere que a «razão nobre», defendida por Kant, entre outros, tem muito mais a ver com a maneira como esses doentes tomam suas decisões do que com a maneira como as pessoas normais decidem. DAMASIO, A. R., 2005, p. 184. 
decorrentes, uma empresa que pode se tornar extremamente complexa (impossível, no limite) sob o ponto de vista estritamente econômico. No entanto, destaca Damásio, antes que este homem inicie os complexos cálculos que uma análise econômica demanda, ao conjecturar acerca das diferentes possibilidades de ação, uma sensação (visceral ou não) poderá estar associada a cenários diversos.

Os marcadores-somáticos são como alarmes automáticos que convergem a atenção para os possíveis resultados negativos de uma determinada decisão, estreitando o leque de possibilidades viáveis ${ }^{45}$. Os marcadoressomáticos, salienta o autor, podem não ser suficientes para a tomada de decisão humana, no entanto, eles aumentarão a precisão e a eficiência do processo de decisão.

Os marcadores-somáticos ${ }^{46}$ são um caso especial do uso de sentimentos que foram criados a partir de emoções secundárias. Estas emoções e sentimentos foram ligados, por via da aprendizagem, a certos tipos de resultados futuros ligados a determinados cenários ${ }^{47}$.

Segundo Damásio, há que se reconhecer uma simbiose entre os processos ditos cognitivos e os chamados processos emocionais ${ }^{48}$. Marcadoressomáticos negativos funcionariam como uma campainha de alarme, chamando a atenção do agente para as possíveis consequências indesejáveis que podem decorrer de uma determinada decisão, enquanto marcadores-somáticos positivos funcionariam como incentivo. Isto não significa que sejamos escravos das emoções, mas que as emoções podem ter um papel destacado no processo de tomada de decisão, dando destaque a determinadas alternativas e rejeitando outras.

Um piloto de avião que precisa fazer um pouso sob condições climáticas desfavoráveis não pode permitir que os sentimentos de pânico lhe invadam de forma a prejudicar sua atenção, no entanto, são os sentimentos que lhe permitem compreender a dimensão e o alcance de suas decisões. Dela dependem, imediatamente, a sua vida, a vida de sua tripulação e passageiros ${ }^{4950}$.

\footnotetext{
${ }^{45}$ DAMASIO, A. R., 2005, p. 185.

46 "Quando lhe surge um mal resultado associado a uma dada opção de resposta, por mais fugaz que seja, sente uma sensação visceral desagradável. Como a sensação é corporal, atribuí ao fenômeno o termo técnico de estado somático (em grego, soma quer dizer corpo); e, porque o estado «marca» uma imagem, chamo-lhe marcador. Repare mais uma vez que uso somático na acepção mais genérica (aquilo que pertence ao corpo) e incluo tanto as sensações viscerais como as não viscerais quando me refiro aos marcadores-somáticos". DAMASIO, A. R., 2005, p. 185.

${ }^{47}$ DAMASIO, A. R., 2005, p. 186.

${ }^{48}$ DAMASIO, A. R., 2005, p. 187.

${ }^{49}$ Exemplo utilizado por Damásio. DAMASIO, A. R., 2005, p. 205-206.

${ }^{50}$ Parece-nos possível estabelecer um diálogo convergente entre Damásio e Nussbaum no tocante à perspectivação da emoção como uma forma de perceber. "Emotions, in short, whatever else they are, are at least in part ways of perceiving". NUSSBAUM, M., 1995, p. 61.
} 
À par do destacado papel das emoções no processo de tomada de decisão racional, algumas vezes elas podem prejudicar a qualidade do raciocínio. Podemos convocar o exemplo hipotético de alguém que prefere dirigir longas distâncias de carro a tomar um avião ${ }^{51}$. Apesar de saber que estatisticamente é muito mais provável ser vítima de um acidente viário do que de um acidente aéreo, muitas pessoas se sentem mais seguras utilizando o transporte viário. Raciocínios deficientes como este provêm daquilo que o investigador alcunha de erro de disponibilidade, ou seja, permite-se que a imagem de um desastre de avião, com toda a sua elevada carga emotiva, domine o panorama do nosso raciocínio e nos conduza a uma decisão defasada em relação à estatística.

\section{1. Para além dos marcadores-somáticos}

Os marcadores-somáticos são essenciais para a construção de uma neurobiologia da racionalidade, mas não são suficientes; salienta Damásio. Diversos processos o precedem, são concomitantes ou agem subsequentemente àquele com vistas a permitir a sua atuação. Quando nos vemos confrontados com uma situação de escolha, uma ampla e variada apresentação dos conhecimentos sobre a situação-problema domina o panorama mental. Várias opções de ação e seus resultados ganham conformação imagética e são trazidos para o centro da atenção. A componente linguística - as palavras e frases que relatam o que a nossa mente vê e ouve - se encontra presente e compete pelo centro da atenção. As estruturas pré-frontais ou os "geradores de diversidade" são supostamente os responsáveis pela justaposição muito variada de imagens em conformidade com o conhecimento previamente adquirido e categorizado. O conhecimento factual é categorizado, ordenado também em função de um determinado valor específico.

O processo de exibição mental só é possível se duas condições se verificarem; a atenção básica e a memória de trabalho. A atenção básica permite a manutenção de uma imagem mental na consciência, com a exclusão relativa de outras. A memória de trabalho mantém ativas diversas imagens separadas, durante um período relativamente extenso ${ }^{52}$. A atenção básica e a memória de trabalho básica são condições fundamentais para a atuação dos marcadores-somáticos que, por sua vez, os intensifica continuamente; numa iniludível circularidade dialética. Segundo o autor, os marcadores-somáticos impulsionam a atenção e a memória de trabalho através do sistema cognitivo. Toda a atividade subsequente à atuação destes mecanismos é estimulada por sinais de que o processo está sendo avaliado positiva ou negativamente ${ }^{53}$.

\footnotetext{
${ }^{51}$ Exemplo utilizado por Damásio. DAMASIO, A. R., 2005, p. 203.

${ }^{52}$ DAMÁSIO, A. R., 2005, p. 208.

53 "Na hipótese global do marcador-somático, proponho que um estado somático, negativo ou positivo, causado pelo aparecimento de uma dada representação, actua não só como marcador do valor do que está representado mas também como intensificador contínuo da memória de trabalho e da atenção. A actividade subsequente é «estimulada» por sinais de que o processo está realmente a ser avaliado, positiva ou negativamente, em termos das preferências e objectivos do indivíduo (...) nos indivíduos normais, os marcadores-somáticos que surgem da activação de uma determinada contingência
} 
O dispositivo de marcação-somática tem suas raízes na regulação biológica, no entanto, se o indivíduo é normal e foi criado em uma cultura relativamente saudável, ele pode conformar-se, por via da educação, às prescrições culturais que se destinam a garantir a sobrevivência em uma sociedade específica. O dispositivo de marcação-somática, portanto, funcionará de forma racional relativamente às convenções sociais e à ética.

Damásio defende que a ação dos impulsos biológicos, dos estados do corpo e das emoções pode ser base indispensável para a racionalidade. A racionalidade não pode ser perspectivada como uma dimensão apartada do corpo, das emoções e dos impulsos; os sinais do corpo, muito provavelmente, configuram e modulam a racionalidade, mesmo quando esta executa as distinções mais sublimes e age em conformidade com elas ${ }^{54}$.

Parece-nos correto afirmar que tanto a abordagem de Damásio quanto a abordagem de Cury são simpáticas à afirmação de Nussbaum de que a leitura de obras literárias pode ser um instrumento valioso no âmbito da tomada de decisão pública. Cury salienta que todas as experiências psíquicas que vivemos - e a leitura de obras literárias deve ser perspectivada como uma rica experiência psíquica - são inscritas na memória, que vai sendo ampliada. A ampliação da memória nem sempre se reflete em termos qualitativos, mas pode se dar em termos qualitativos. A leitura de obras literárias, enquanto potencialmente capazes de nos proporcionar ricas experiências psíquicas, pode influenciar no processo de construção do "eu sou" que se refletirá em suas decisões. A imaginação literária pode ser perspectivada como uma rica experiência psíquica que sofrerá o caos psicodinâmico e será armazenada na memória.

Segundo Damásio, as emoções podem ter um papel destacado no âmbito da tomada de decisão racional. As emoções são fundamentais para a perspectivação adequada de determinadas situações-problemas ${ }^{55}$ e ofereceriam boas dicas quanto à sua solução.

\section{O ESPECTADOR JUDICIOSO}

As emoções podem ser racionais ou irracionais normativamente. ${ }^{56}$. As emoções racionais, afirma Nussbaum, desempenhariam um iniludível e fundamental papel no âmbito da tomada pública de decisão e é, portanto, premente distinguí-las. O espectador judicioso - conceito criado por Adam Smith - é perspectivado pela autora como o dispositivo capaz de proceder a esta

impulsionam a atenção e a memória de trabalho através do sistema cognitivo”. DAMÁSIO, A. R., 2005, p. 208-209.

${ }_{55}^{54}$ DAMÁSIO, A. R., 2005, p. 210-211.

55 Tanto em Nussbaum, quanto em Damásio, as emoções são compreendidas como dimensões essenciais ao menos em alguns casos - para a correta perspectivação do caso-problema e de seu alcance.

56 Nussbaum sustenta que emoções como a repugnância ou a aversão têm um conteúdo cognitivo específico que torna a sua confiabilidade duvidosa na vida social e, especialmente, no âmbito do Direito. Para o desenvolvimento desta afirmação. NUSSBAUM, 1999, p. 19-62. 
"filtragem" e a leitura literária como um exercício capaz de construir artificialmente a posição de tal espectador ${ }^{57}$.

O espectador judicioso não está pessoalmente comprometido com os interesses das partes, seu julgamento está livre da influência de sentimentos como a sua segurança pessoal ou a sua felicidade, o que nos capacitaria a afirmar que o seu julgamento é imparcial. Ele não está privado de emoções e sua análise não objetiva suprimí-las. Estabelece-se, entre espectador e parte, uma relação de compaixão ${ }^{58}$. A sua participação empático-emotiva com a estória $^{59}$ narrativamente construída e apresentada lhe permitiria alcançar um grau de compaixão racional em face do sofrimento alheio.

O espectador judicioso pode convocar informações de sua história pessoal, mas estas informações devem ser examinadas criticamente a fim de que não se torne tendenciosa a sua decisão - sentença travestida de imparcialidade mas que, no fundo, satisfaz seus próprios objetivos e projetos.

Uma de suas faculdades mais importantes, afirma Nussbaum, é a capacidade que tem de imaginar o que significa estar no lugar de cada uma das pessoas envolvidas na situação fático-problemática que se delineia à sua frente, sem qualquer comprometimento pessoal com o resultado da contenda ${ }^{60}$. O espectador experiencia sentimentos em face dos casos-problemas que se lhe apresentam, como resultado de sua vívida imaginação. Não obstante, enquanto espectador e não participante, estas emoções não o conduzem cegamente, turvando sua capacidade de decidir racionalmente. A medida racional do infortúnio é perspectivada como elemento essencial de uma decisão justa.

As emoções podem ser bons guias e para que efetivamente o sejam são necessários que: a) o julgador tenha uma visão abrangente e real do casoproblema; b) perspective a real dimensão do seu sentido e importância para as partes envolvidas; c) a emoção seja a de um espectador e não a de um participante. Isto implica pelo menos duas questões: $\mathrm{C}$ a.) que deve buscar

\footnotetext{
${ }^{57}$ NUSSBAUM, M., 1995, p. 72.

${ }^{58}$ A relação que se estabelece entre o espectador judicioso e as partes envolvidas na situação-problema sob análise ultrapassa a simples empatia. Segundo Nussbaum, o espectador judicioso se interessa pelos participantes como um amigo preocupado. Neste sentido, NUSSBAUM, M., 1995, p. 73.

${ }^{59}$ Rubem Alves advoga a volta do termo "estória", assassinada pelos gramáticos, denuncia o pensador. No nosso entender, a reabilitação gramatical do termo "estória" está justificada por um apelo fenomenológico e se justifica, para além, segundo uma concepção da história enquanto memória, nos termos sugeridos por Cury. A história acontece no mundo de dentro, sempre. "Estória não quer se tornar história", como corretamente pontuou Guimarães Rosa. De nosso lado, compreendemos ser correto acrescentar a seguinte perturbação: “que história?". Cf. ALVES, Rubens. Sobre Dicionários e necrotérios. In: Aprendiz. Disponível em: http://www2.uol.com.br/aprendiz/n_colunas/r_alves/id010201.htm. Data do acesso: 30 de setembro de 2011.

60 "In all such cases, that there may be some correspondence of sentiments between the spectator and the person principally concerned, the spectator must, first of all, endeavour, as much as he can, to put himself in the situation of the other, and to bring home to himself every little circumstance of distress which can possibly occur to the sufferer. He must adopt the whole case of his companion with all its minutest incidents; and strive to render as perfect as possible, that imaginary change of situation upon which his sympathy is founded". SMITH, A., 1759, p. 71.
} 
compreender dedutivamente se os participantes compreenderam corretamente e reagiram de forma racional aos problemas; c.b.) que deve impedir que seu interesse pessoal em seu bem estar comprometa a análise da situaçãoproblema $^{61}$.

O exercício de leitura de obras literárias é perspectivado por Nussbaum, na esteira de Smith, como um recurso metodológico-pedagógico essencial. Ao lermos uma obra literária ocupamos artificialmente o lugar de espectadores judiciosos, ou seja, espectadores preocupados que se identificam, em certa medida, com os dramas vivenciados pelas personagens, enquanto dramas humanos. Não é toda obra literária que nos permite experienciar a posição ideal de espectadores judiciosos, adverte Nussbaum ${ }^{62}$. O leitor deve assumir uma postura duplamente crítica, ou seja, deve selecionar criticamente quais obras estariam mais inclinadas a servir a esta finalidade e, durante o processo de leitura, resistir aos apelos da prosa bem construída e da estética apelativa a fim de manter uma postura crítico-reflexiva, ancorada em valorações ético-morais e políticas.

À par da assunção de uma necessária postura crítico-reflexiva em face da obra e da experiência literária, enquanto experiência emotiva, há que se reconhecer, com Nussbaum, que a estrutura formal implícita na experiência literária pode nos levar a experienciar sentimentos racionais e tal exercício tem a potencialidade de contribuir para o refinamento de nossa capacidade crítica e empático-emocional.

\section{OS POETAS COMO JUÍZES}

O juiz deve ser o árbitro da diferença. Para desempenhar bem o seu papel, ele deve ser capaz de proceder a juízos equânimes, em consonância com as complexidades históricas e humanas. A maioria dos juízes, sustenta Nussbaum, não julga assim. É necessário, portanto, que os juízes deixem de julgar como juízes e passem a julgar como poetas-juízes ${ }^{63}$. O poeta-juiz é aquele que perspectiva as circunstâncias reais do caso concreto e que compreende empático-emocionalmente (enquanto espectador) o seu sentido e alcance para cada uma das pessoas envolvidas na querela. Assim com a luz do sol é capaz de iluminar cada curva, cada recôncavo de uma criatura desamparada, o julgamento do poeta-juiz seria capaz de perceber e revelar cada detalhe escondido $^{64}$ (ou não relevado por concepções formalistas do Direito). A

\footnotetext{
${ }^{61}$ NUSSBAUM, M., 1995, p. 73.

62 "In short, my view does not urge a naive uncritical reliance on the literary work". NUSSBAUM, M., 1995 , p. 76.

63 “The poet does not judge "as judge judges”. NUSSBAUM, M., 1995, p. 81.

64 "We can best get an idea of what his procedure is like, he suggests, by thinking of the way sunlight falls around a "helpless thing". This bold image suggests, first, enormous detail and particularity. When he sun falls around a thing it illuminates every curve, every nook; nothing remains hidden, nothing unperceived. So, too, does the poet's judgment fall, perceiving all that is there and disclosing it to our view". NUSSBAUM, M., 1995, p. 81.
} 
verdadeira imparcialidade pressupõe uma rica e concreta visão da situação problema - enquanto narrativa singular - que faça justiça à vida humana.

A resposta jurisdicional deve sublimar a pura empatia e alcançar a valoração - a partir do ponto de vista do julgador - do sentido do sofrimento das partes e suas implicações. Não obstante, esclarece Nussbaum, tal exercício criativo tem limites bem definidos no âmbito da realização do direito.

O raciocínio técnico-legal, o conhecimento da lei e os constrangimentos dos precedentes ${ }^{65}$ têm um papel central no âmbito da realização do direito. Estes constrangimentos legais são perspectivados como limites dentro dos quais a imaginação deve trabalhar. No âmbito do raciocínio judicial, deve-se adicionar ao modelo do espectador judicioso de Smith os constrangimentos institucionais lato sensu a fim de se alcançar uma resposta juridicamente adequada ${ }^{66}$.

Tendo em vista todo o exposto, resta ponderar. O modelo de neutralidade judicial construído por Nussbaum compreende e respeita a autonomia do direito e a especificidade do seu horizonte? Concordamos com Linhares que o modelo construído por Nussbaum reproduz todos os pressupostos de um discurso da área aberta, uma vez que estão iniludivelmente presentes em sua proposta: o reconhecimento da insuficiência normativa de regras e princípios (materiais jurídicos) e a assunção imediata de que tal insuficiência só pode ser vencida pela imaginação literária e pelas intenções que esta introduz; a distinção dicotômica dos casos jurídicos em fáceis e difíceis e a imediata conclusão de que a imaginação literária só seria importante no âmbito dos casos difíceis e o tratamento indiscriminado dos materiais jurídicos como constrangimentos institucionais ${ }^{67}$.

A dicotomia casos fáceis e casos difíceis, no âmbito da proposta de Nussbaum, é possível porque a autora assume acrítica e aprobblematicamente que os materiais jurídicos, enquanto prescrições normativas, possuiriam um sentido abstrato acabado, convocável através de um exercício lógico-racional. Para alguns casos jurídicos (casos fáceis) haveria uma resposta disponível no sistema de normatividade (compreendido como um sistema finito, com fronteiras bem delimitadas). Uma resposta que dispensaria, como assume Nussbaum, a mediação de um juiz imaginativo. Todo o potencial da imaginação literária, ao fim e ao cabo, é reduzido a uma teoria para os casos difíceis.

O modelo construído por Nussbaum não alcança seu objetivo primordial de provocar mudanças práticas no âmbito da realização do direito porque não compreende a verdadeira natureza desta realização, condenando fatalmente o julgador a buscar para além do Direito o critério para sanar as insuficiências normativas dos seus materiais.

\footnotetext{
${ }^{65}$ É importante relevar que os precedentes possuem papel e força diferenciada no âmbito dos sistemas de common law, horizonte do qual parte Martha Nussbaum.

66 "Where legal reasoning is concerned, we need to add to Smith's model the fact that there will also be powerful institutional constraints on the judge reasoning”. NUSSBAUM, M., 1995, p. 87-88.

${ }^{67}$ LINHARES, M. A., 2010, p. 289.
} 
É extremamente interessante e frutífera a análise que Nussbaum desenvolve acerca da dimensão cognitiva das emoções. As emoções, concordamos com a autora, podem ser racionais e desempenhar um papel essencial na tomada pública de decisão. Estudos atuais no âmbito das neurociências e da psicologia corroboram esta afirmação e parecem assentir vigorosamente com a assunção de que a experiência imaginativa, enquanto exercício pático-emocional (realidade psíquica), teria a potencialidade de contribuir para a construção de um "eu sou" mais receptivo, inclusive, ao sofrimento alheio.

A leitura de obras literárias, enquanto recurso pedagógico, pode contribuir para a construção de um operador do direito mais sensível à diferença e capaz de oferecer respostas mais adequadas para os casos-problemas surgidos no mundo da vida. No entanto, há que se reconvocar a objeção pontualmente assinalada supra acerca de quais obras deveriam ser convocadas para tal empresa. A experiência imaginativa é também uma experiência significativamente solitária, na qual incidem variáveis diversas como a história de vida do leitor, o seu contexto atual etc. Não há, portanto, como definir, a priori, quais obras poderiam ser perspectivadas como obras adequadas para o exercício empático-emocional do espectador judicioso, ainda que se concorde com Nussbaum acerca do contributo diferenciado da experiência literário-emocional propiciada por obras pertencentes ao gênero realista. Uma obra perspectivada como "inadequada", a priori, pode, potencialmente, proporcionar uma rica experiência imaginativa e empáticoemotiva de substancial valor âmbito da tomada pública de decisão. A mesma objeção pode ser convocada para defender a utilização de outro recursos, tais como a obra cinematográfica. Parece-nos apressada e simplista a afirmação de que a experiência imaginativa proporcionada pela obra literária é sempre superior qualitativamente à obra cinematográfica. Obras cinematográficas minimalistas, como Dog Ville, por exemplo, que são tão potencialmente capazes de proporcionar uma rica experiência imaginativa quanto uma obra literária. Para além, se o objetivo da convocação da obra literária é proporcionar ao seu espectador a experiência da piedade, talvez o forte apelo estético da obra cinematográfica seja um fator positivo a ser relevado.

\section{CONSIDERAÇÕES FINAIS}

O Direito deve levar à sério as emoções. Concluímos, com a autora, que algumas emoções podem ser racionais e que a assunção destas emoções no âmbito da tomada pública de decisão pode conduzir os juízes a decisões práticoprudencialmente mais adequadas. A castração das emoções, contrariamente ao que afirma acriticamente o senso comum, pode desembocar em injustiça material.

Os operadores do Direito não podem se conformar com a justiça formal. A resposta prático-prudencialmente adequada só o será se o julgador compreender o problema jurídico de forma abrangente e for capaz, para além, de perspectivar a sua dimensão e o seu alcance para cada uma das partes 
envolvidas. Esta relação pode (e deve, segundo Nussbaum) ultrapassar a mera empatia, mas não pode nunca se converter em paixão. A atividade jurisdicional não deve ser perspectivada como trincheira ou instrumento para a consecução de fins exteriores ao Direito.

O exercício imaginativo, suscitado pela leitura de obras literárias e outros meios, pode ser pedagogicamente interessante. A experiência imaginativa pode nos proporcionar a experienciação de emoções como a piedade; fundamental no âmbito da tomada de decisão pública e privada.

O cruzamento da literatura com o Direito pode ser pedagogicamente frutífero no âmbito da educação jurídica assumida holisticamente. Não obstante, a instrumentalização da literatura para a resolução de casos difícíeis - o que parece propor Nussbaum, ao fim e ao cabo - parece não compreender a especificidade do Direito nem os potenciais contributos da imaginação literária (tão salientados pela filósofa!) no âmbito da realização prática do Direito. A autora reduz a complexidade do fenômeno jurídico, enquanto criação culturalsocial-política-jurídica, a um conjunto de "materiais jurídicos" normativamente insuficientes. Não obstante, o sistema jurídico deve ser corretamente perspectivado como uma tarefa aberta à intencionalidade problemática dos casos-problema surgidos no mundo da vida. O sentido das proposições normativas não está, pois, pronto e acabado (estabilizado, ainda que hipoteticamente) mas concretiza-se significativamnte à luz dos casos-problemas que é chamado a resolver.

A realização do Direito cumpre-se segundo uma dialética infindável entre as dimensões do sistema e do problema jurídico. A redução do sistema jurídico a um conjunto de materiais jurídicos, significativamente determinados e estabilizados, permite que Nussbaum lance mão da literatura e da imaginação literária como um instrumento necessário, mas secundário, para a consecussão dos ideiais da justiça prático-judicativa. No entanto, assunção da dimensão do problema enquanto prius metodológico da realização do Direito - horizonte do qual emanam interrogativamente as perguntas suscitadas pelo caso e para o qual convergem as respostas analogico-hipoteticamente convocadas - e do sistema enquanto problema aberto à interrogação perscrutante do caso (segundo uma orientação nomeadamente jurisprudencialista), convoca-nos a assumir de maneira mais radical e luminosa os potenciais da imaginação literária e das emoções racionais no âmbito da realização prática do Direito.

\section{REFERÊNCIAS}

ALVES, Rubens. Sobre Dicionários e necrotérios. In: Aprendiz - UOL, http://www2.uol.com.br/aprendiz/n_colunas/r_alves/id010201.htm. Data do acesso:

BAUMAN, Zigmunt. Modernidade e Holocausto. trad. Marcus Penchel, Rio de Janeiro: Jorge Zahar Ed., 1998.

CURY, Augusto Jorge. Inteligência multifocal: análise da construção dos pensamentos e da formação de pensadores. $8^{\mathrm{a}}$ ed. rev., São Paulo: Cultrix, 2006. 
DAMASIO, Antônio R. O erro de Descartes: Emoção, razão e cérebro humano. $24^{a}$ ed., Mem Martins: Publicações Europa-América, 2005.

DARWIN, Charles. A origem das espécies. São Paulo: Martin Claret Ed., 2004.

DWORKIN, Ronald. Uma questão de princípio. São Paulo: Martins Fontes, 2005.

ECO, Humberto. Os limites da interpretação. trad. José Colaço Barreiros, Lisboa: Difel, s/d.

KAUFMANN, A.; HASSEMER, W.. Introdução à Filosofia do Direito e à Teoria do Direito contemporâneas. trad. Marcos Keel e Manuel Seca de Oliveira, Lisboa: Calouste Gulbenkian, 2002.

LINHARES, José Manuel Aroso, Imaginação literária e "Justiça Poética" - Um discurso da "área aberta"? In: Direito e Literatura: discurso, imaginário e normatividade, Porto Alegre: Nuria Fabris Ed., 2010.

NEVES, A. Castanheira. Metodologia jurídica: problemas fundamentais. Coimbra: Coimbra editora, 1993.

NUSSBAUM, Martha. Poetic Justice: the literary imagination and public life. Boston: Breacon Press, 1995.

, Martha. Secrets sewers of vice In: The Passions of Law. New York: New York University press, 1999.

, Martha. Upheavals of thought: the intelligence of emotions. Cambridge: Cambridge University Press, 2001.

ORLANDI, Eni. Análise de discurso: Princípios e procedimentos. $3^{\mathrm{a}}$ ed., Campinas: Pontes, 2001.

PLATÃO. Fédon. trad. Carlos Alberto Nunes, versão eletrônica disponível em http://pt.scribd.com/doc/6986625/Platao-FEDON-a-Imortalidade-Da-Alma. Data de acesso: 30/09/2011.

SMITH, Adam. The theory of moral sentiments. vol. 1, Liberty Fund. Org., 1759.

VILA, Marisa Iglesias. El problema de la discreción judicial: uma aproximación al conocimiento jurídico. Madrid: Centro de Estúdios Políticos y Constitucionales, 1999.

VILLELA-PETIT, Maria da Penha. Platão e a poesia na república in: Kriterion: Revista de filosofia, vol. 44, $\mathrm{n}^{\circ}$ 107, junho de 2003,

http://www.scielo.br/scielo.php?pid=S0100512X2003000100005\&script=sci_arttext. Acesso em: 5 jan. 2011.

Recebido em 30-09-2011

Avaliado em 14-11-2011

Aprovado para publicação em 05-12-2011 